\title{
CT-guided stereotactic biopsies using a Modified frame and Gildenberg techniques
}

\author{
DENNIS E BULLARD, ${ }^{*} \dagger$ BLAINE S NASHOLD, JR., ${ }^{*}$ DENNIS OSBORNE, $\ddagger$ PETER C \\ BURGER, $\dagger$ PHILIP DUBOIS $\ddagger$
}

From the Departments of Surgery (Neurosurgery), * Pathology (Neuropathology), $\dagger$ Radiology

(Neuroradiology), $\ddagger$ and Medicine (Neurology), Duke University Medical Center, Durham, NC, USA

SUMMARY Eighteen patients underwent CT guided stereotactic biopsies using either a Riechert-Mundinger stereotactic frame modified for use in the CT scanner or the CT-based intracranial landmark technique of Gildenberg and a Todd-Wells frame. In seven patients undergoing biopsy with the modified frame technique, representative tissue samples were obtained in all cases. Eleven patients had biopsies using the Gildenberg technique and representative tissue samples were obtained in 10 of the 11 . No major postoperative complications occurred in either group. Both techniques allowed samples of intracranial tissue to be obtained safely and efficiently. The modified frame technique provided a higher degree of accuracy while the Gildenberg technique required significantly less CT time and provided a satisfactory degree of accuracy. In seven patients with ring enhancing lesions, biopsies of the enhancing rim provided diagnostic tissue while biopsy of the central low density center of the lesion in three patients provided necrotic material which was useful in histologically grading the tumour.

Computed tomography (CT) has allowed stereotactic biopsies of intracranial lesions to be performed with a high degree of accuracy and safety utilising multiple techniques. ${ }^{1-11}$ The majority of these methods have used a stereotactic frame fixed to the patient at the time of CT scan.' 2479 These frames have been either modifications of conventional stereotactic frames or frames developed specifically for use in the CT scanner. While they have been used safely and effectively, a major criticism has been the large amount of CT time required. It has been proposed that a CT scanner be dedicated for this purpose, ${ }^{8}$ but most institutions have not been able to justify this expense. An alternative system has been to use either external landmarks attached to the patient's skull during the CT scan or to utilise intracranial landmarks directly determined from the CT scan to calculate intracranial target points. ${ }^{591213}$ This alternative system used less CT time but its relative accuracy and safety have not been established. In the past 3 years, we have used both techniques and have had the opportunity to compare

Address for reprint requests: DE Bullard, MD, Division of Neurosurgery, Duke University Medical Center, Box 3128, Durham, North Carolina, 27710, USA.

Received 18 October 1983. Accepted 5 January 1984 their relative advantages and disadvantages. The results of that comparison are the subject matter of this report. A brief preliminary account of this work has been reported elsewhere. ${ }^{14}$

\section{Material and methods}

\section{Patient selection}

For surgically accessible lesions, a standard craniotomy is considered to be the procedure of choice. ${ }^{15}$ Stereotactic biopsies are performed on patients with deep, surgically inaccessible lesions or in patients where a preliminary biopsy diagnosis would influence the final surgical procedure. The first seven patients were biopsied utilising the modified frame technique (table 1 ). The next 11 patients had biopsies performed with the Gildenberg technique (table 2).

Modified frame technique A standard RiechertMundinger stereotactic frame was modified for direct use in the CT scanner (fig 1). ${ }^{4}$ Four rod sets were attached to the base ring, centred at $0^{\circ}, 90^{\circ}, 180^{\circ}$ and $270^{\circ}$. Each of these rod sets consisted of two perpendicular lucite rods $18 \mathrm{~mm}$ in diameter and $12 \mathrm{~cm}$ high. The two perpendicular rods were connected by a slanted rod, which had a diameter of $6 \mathrm{~mm}$. These rods were mounted on a flat aluminum plate, which was fixed to the base by a set of screws. The attached rod system allowed adequate space for the attachment of the frame to the head by stainless steel 
Table 1 CT guided stereotactic surgery: Modified Frame technique

\begin{tabular}{|c|c|c|c|c|}
\hline $\begin{array}{l}\text { Case } \\
\text { No. }\end{array}$ & $\begin{array}{l}\text { Age/Sex } \\
(y r)\end{array}$ & Clinical state & CT appearance & Diagnosis \\
\hline 1 & $59 / \mathrm{F}$ & $\begin{array}{l}\text { Acute L hemiparesis; Plasma cell } \\
\text { pneumonitis }\end{array}$ & $\begin{array}{l}\text { Non-enhancing low density mass } \mathbf{R} \\
\text { basal ganglia }\end{array}$ & Mucormycosis \\
\hline 2 & $16 / \mathrm{M}$ & $\begin{array}{l}6 \text { mom subacute } \mathrm{R} \text { hemiparesis; } \\
\mathrm{Hx} \text { rheumatic fever; Fever and chills } \\
1 \text { mom prior }\end{array}$ & $\begin{array}{l}\text { Ring-enhancing mass } \mathrm{L} \text { internal } \\
\text { capsule }\end{array}$ & $\begin{array}{l}\text { Pilocytic } \\
\text { astrocytoma }\end{array}$ \\
\hline 3 & $6 / F$ & $\begin{array}{l}\text { Subacute onset of } L>R \downarrow \text { visual } \\
\text { acuity over } 1 \text { yr }\end{array}$ & $\begin{array}{l}\text { Multilobulated ring enhancing } \\
\text { suprasellar mass; hydrocephalus; } \\
\text { calcification }\end{array}$ & Gliotic Tissue \\
\hline 4 & $44 / M$ & $\begin{array}{l}3 \text { yr Hx of progressive } R \text { hand weakness; } \\
2 \text { mom Hx of dysphasia }\end{array}$ & $\begin{array}{l}\text { Non-enhancing low density mass } \\
\text { L basal ganglia }\end{array}$ & $\begin{array}{l}\text { Necrosis and } \\
\text { perivascular } \\
\text { cuffing }\end{array}$ \\
\hline 5 & $37 / \mathbf{M}$ & $\begin{array}{l}\text { S/P L orbital meningioma and radiation; } \\
\text { S/P infection; acute onset seizures }\end{array}$ & Ring-enhancing $\mathrm{L}$ frontal lesion & Radionecrosis \\
\hline 6 & $45 / \mathrm{M}$ & $\begin{array}{l}\text { S/P L parietal GBM and radiation; } \\
\text { recent worsening of seizures and } \\
R \text { hemiparesis }\end{array}$ & $\begin{array}{l}\text { Multilobulated ring-enhancing } \mathbf{L} \\
\text { parietal mass }\end{array}$ & $\begin{array}{l}\text { Glioblastoma } \\
\text { multiforme }\end{array}$ \\
\hline 7 & $26 / \mathrm{M}$ & $\begin{array}{l}\text { Low density lesion } R \text { internal capsule; } \\
\text { radiation and chemotherapy } 4 \mathrm{yr} \\
\text { before; } 3 \text { mom deterioration }\end{array}$ & Small enhancing mass deep white matter & $\begin{array}{l}\text { Anaplastic } \\
\text { astrocytoma }\end{array}$ \\
\hline
\end{tabular}

clamps and free movement of the "bow" of the Riechert-Mundinger frame. Software modification to the Pfizer 0450 CT scanner was made to allow the input of the position of the localising rods and the target points using the cursor on the CT console. In order to allow this system to be used on alternative CT scanners, a similar computer program for the transformation of the CT coordinates to stereotactic coordinates was also developed for a handheld programmable calculator (Hewlett Packard HP-41 $\mathrm{CV}$, Andover, MA). Patients were prepared either in the operating room or in adjacent quarters in the radiology department and had the CT modified stereotactic frame attached to their head. They were then brought into the CT scanner where a standard enhanced scan was performed. The $\mathrm{X}, \mathrm{Y}$, and $\mathrm{Z}$ coordinates were determined on either the computer console, or the hand-held computer, and the trajectory was established on the Riechert-Mundinger Phantom ring. A burr hole was then placed either while the patient was in the CT scanner or in the operating room. A biopsy needle was then used to obtain a tissue sample. If the biopsy was performed in the CT suite, determination of the exact position of the stereotactic needle could be subsequently performed by a CT scan while the needle was in place.

Gildenberg technique An enhanced CT scan was made on any scanner which allows a lateral scout view and gantry tilt adjustment to be performed (fig 2). In this way, the scan could be done through a baseline that included bony landmarks which could be later duplicated on a lateral skull film in the operating room. The slice through the bony landmarks was designated the reference slice. After the scan was completed, multiple target points were selected using the computer console. Each target point was given an alphabetical letter for identification. A zero slice was then selected to establish the zero point. The zero slice

Table 2 CT guided stereotactic surgery: Gildenberg technique

\begin{tabular}{|c|c|c|c|c|}
\hline $\begin{array}{l}\text { Case } \\
\text { No. }\end{array}$ & $\begin{array}{l}\text { Age/Sex } \\
(y r)\end{array}$ & Clinical state & CT appearance & Diagnosis \\
\hline 8 & $68 / \mathrm{M}$ & Progressive $\mathrm{L}$ hemiparesis & Enhancing $\mathbf{R}$ thalamic Lesion & $\begin{array}{l}\text { Anaplastic } \\
\text { astrocytoma }\end{array}$ \\
\hline 9 & $42 / \mathrm{F}$ & 4 Yr Hx partial elementary seizures & $\begin{array}{l}\text { Non-enhancing low density lesion in } \\
\text { deep of } \mathbf{R} \text { hemisphere }\end{array}$ & $\begin{array}{l}\text { Anaplastic } \\
\text { astrocytoma }\end{array}$ \\
\hline 10 & $42 / \mathrm{F}$ & $\begin{array}{l}\mathbf{L} \text { temporal astrocytoma } \mathbf{S} / \mathbf{P} \text { radiation } \\
\mathbf{R x}\end{array}$ & $\begin{array}{l}\text { Ring-enhancing lesion in deep } \mathrm{L} \\
\text { hemisphere }\end{array}$ & $\begin{array}{l}\text { Radiation } \\
\text { necrosis }\end{array}$ \\
\hline 11 & 73/M & Adult onset seizures & $\begin{array}{l}\text { Mildly enhancing low density lesion } \\
\text { L frontal lobe }\end{array}$ & $\begin{array}{l}\text { Anaplastic } \\
\text { astrocytoma }\end{array}$ \\
\hline 12 & $58 / \mathrm{F}$ & $\begin{array}{l}\text { Acute L hemiparesis } 1 \text { yr prior; recent } \\
\text { progression over } 2 \text { wk }\end{array}$ & Ring enhancing lesion $\mathbf{R}$ basal ganglia & $\begin{array}{r}\text { Glioblastoma } \\
\text { multiforme }\end{array}$ \\
\hline 13 & $59 / \mathrm{F}$ & 1 mom speech, leg and bladder & $\begin{array}{l}\text { Ring enhancing lesion deep } R \text { frontal } \\
\text { lobe and corpus callosum }\end{array}$ & $\begin{array}{r}\text { Glioblastoma } \\
\text { multiforme }\end{array}$ \\
\hline 14 & $15 / \mathbf{M}$ & 2 wk severe headache & Ring enhancing $L$ thalmic mass & $\begin{array}{r}\text { Glioblastoma } \\
\text { multiforme }\end{array}$ \\
\hline 15 & $58 / \mathrm{F}$ & Generalised seizure 1 mom prior & $\begin{array}{l}\text { Low density enhancing lesion } \mathbf{L} \\
\text { postero-medial temporal lobe }\end{array}$ & $\begin{array}{r}\text { Glioblastoma } \\
\text { multiforme }\end{array}$ \\
\hline 16 & $70 / F$ & Progressive dementia & $\begin{array}{l}\text { Enhancing lesion posterior corpus } \\
\text { callosum }\end{array}$ & $\begin{array}{r}\text { Glioblastoma } \\
\text { multiforme }\end{array}$ \\
\hline 17 & $36 / \mathrm{F}$ & $\begin{array}{l}\text { Pituitary adenoma resected; }+4500 \\
\text { rads } 10 \text { yrs prior; } 2 \text { wk } R \text { hemiparesis }\end{array}$ & Ring enhancing $L$ periventricular mass & $\begin{array}{r}\text { Glioblastoma } \\
\text { multiforme }\end{array}$ \\
\hline 18 & $58 / \mathrm{F}$ & 2 yr Hx headaches & Multiple small enhancing lesions & $\begin{array}{l}\text { Metastatic } \\
\text { carcinoma }\end{array}$ \\
\hline
\end{tabular}




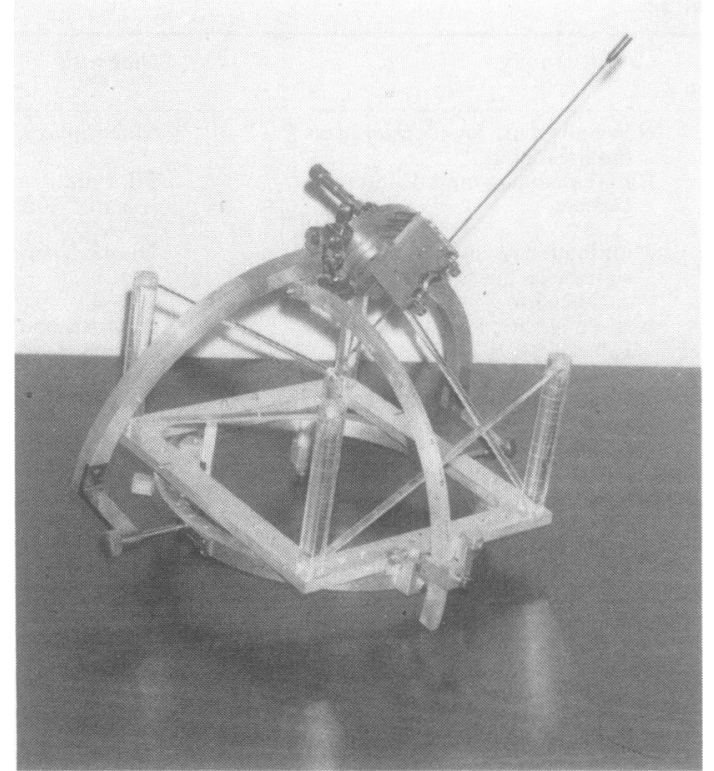

Fig 1 A standard Riechert-Mundinger Stereotactic frame modified for direct utilisation in the CT scanner. Four lucite rod sets were attached to a fat aluminium base plate allowing calculation of intracranial target points using the CT console or a hand-held programable calculator.

may be at any distance from the reference slice. This slice was used to established the midway point between the outer and inner tables of the skull (fig 3 ). The zero point was then subsequently displayed on all slices. For each of the target points, their AP and lateral relationships to this zero point were determined on the appropriate slice utilizing the CT cursor (fig $4 a, b)$. From this data, the AP coor-

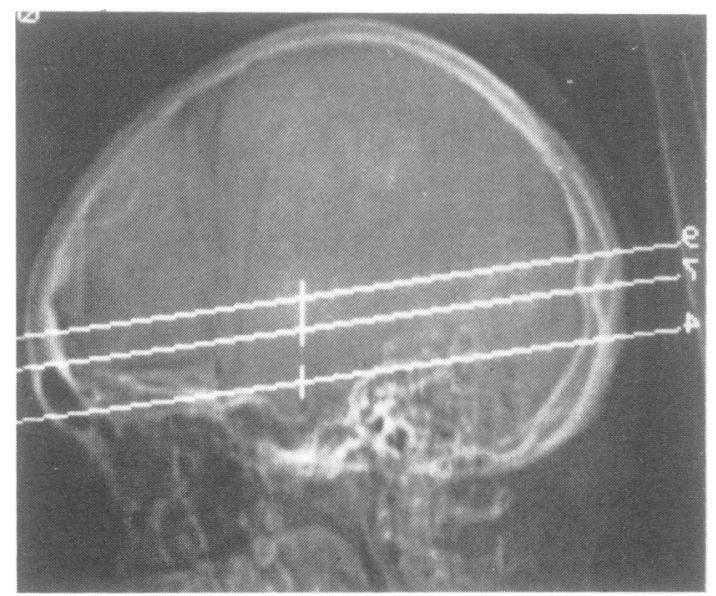

Fig 2 A lateral scout film on the GE 8800 CT scanner demonstrating the reference slice that includes reproducible bony landmarks.

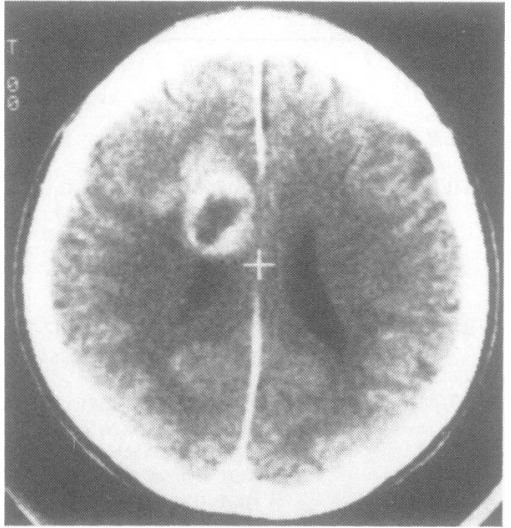

Fig 3 The zero point, which represents a point midway between the anterior and posterior and the 2 lateral bony boundaries, is demonstrated. This zero point is subsequently displayed on all CT slices and is used as the reference point for all target determinations.

dinate $(\mathrm{X})$ and the lateral coordinate $(\mathrm{Y})$ were established. The vertical coordinates $(Z)$ are determined for each target point by the distance of the target slice from the reference slice. A table was compiled utilizing all of the CTgenerated data. On this table, each target designated by a letter was identified by its parameters: the slice on which the target appears and its distance from the reference slice, which represents the vertical coordinate $(Z)$, the relationship of the target to the zero point on the AP axis (X) and the lateral relationship of the target to the zero point $(Y)$.

The stereotactic surgery was then performed in the operating room with any stereotactic frame. A burr hole was placed and the patient was positioned in the stereotactic frame. Standard AP and lateral radiographs were taken. The line representing the reference slice was drawn on the lateral film using the bony landmarks from the CT scan scout film. The line representing the zero slice was then drawn on the same lateral film at the appropriate distance above the reference slice after correcting for appropriate magnification factors. On this zero slice, the midposition between the outer tables of the frontal and occipital bones was marked. Using these two lines, all necessary parallel target lines could be drawn. A line perpendicular to all of these parallel targets lines was then made through the zero point. This perpendicular line identified the zero point that will be seen on each of the CT slices. With the zero point identified on the lateral skull film, the prior AP calculations for each target point could be marked on the lateral film using the appropriate magnification factors. From the AP radiograph, the relationship of the exact midline of the skull to the midline of the stereotactic frame could be established. Then, the distance from the midline to the target point, as established from the CT scan, could be noted.

The stereotactic frame was then adjusted so that the coordinates for the first target point coincides with the target point of the apparatus. Radiographs confirming this were taken and a stereotactic biopsy needle was inserted to the 

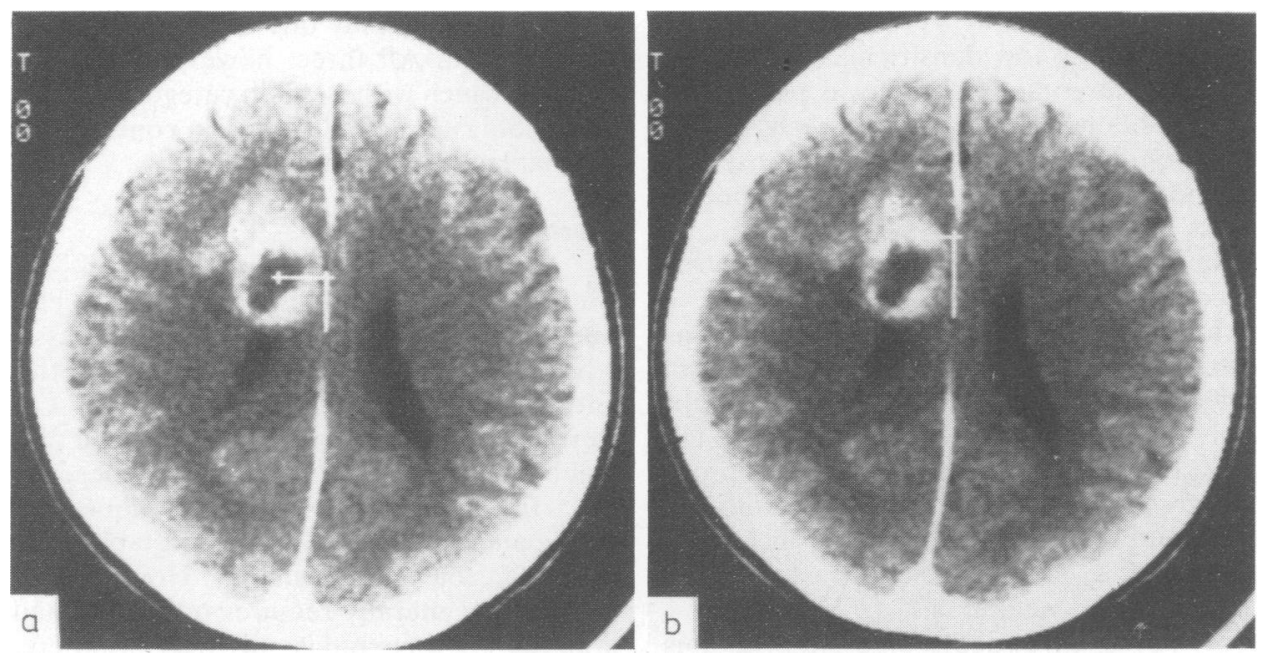

Fig 4 CT scans showing target points in the low density centre (a) and the enhancing rim (b) of a ring enhancing lesion. All target points are defined in relationship to the zero point.

target point (fig 5). At this institution, a blunt-tipped, metal biopsy needle with a $1 \mathrm{~cm}$ side port has been used. Within the outer needle is an identical smaller needle with a similar sized side port. The side port is inserted to the target point and, under suction, the inner needle is rotated within the outer needle, thus cutting a core of tissue within the inner needle. The specimen obtained is a cylinder of tissue $2 \times 20 \mathrm{~mm}$. At the target point, from one to four quadrant biopsies are obtained and sent for frozen section. While the frozen section is being performed, the second target point is selected, but the needle is not inserted unless the initial specimen is not diagnostic. The lesion is biopsied until a definitive diagnosis is made or it becomes apparent that such a diagnosis must await permanent sections.

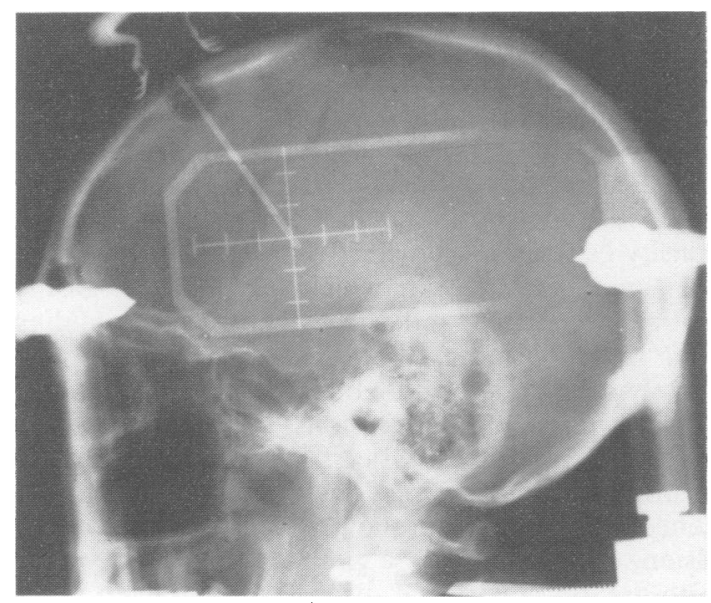

Fig 5 An intraoperative lateral skull film showing the biopsy needle inserted to the target point.
Target point selection For each patient, there is individual selection of the target point. For most ring enhancing lesions, target points are selected both within the low density centre and at the enhancing margin of the mass. If the lesion is a tumour, this allows both the cellular neoplastic tissue in the enhancing rim and a portion of the necrotic centre to be obtained (fig $4 a, b$ ). The latter is used as a histologic feature to distinguish the glioblastoma multiforme from gliomas of lower grade.

\section{Results}

\section{MODIFIED FRAME TECHNIQUE}

Utilizing the modified Riechert-Mundinger frame, 7 patients were evaluated (table 1). The first four patients have been previously reported." In five of the seven patients, a satisfactory tissue diagnosis was achieved. One of these patients had mucormycosis, three had primary brain tumours, and one had radionecrosis subsequent to treatment for a meningioma. In two of the seven patients, the tissue obtained was not diagnostic and a secondary open procedure was required. In one of these patients (case three), a multilobulated suprasellar mass was felt preoperatively to represent either a craniopharyngioma or a hypothalamic glioma. Hypercellular glial tissue was obtained by the stereotactic procedure. Subsequently, an open craniotomy was performed. Tissue identical to that obtained by the stereotactic procedure was again obtained but because of the quantity and better cellular detail, the diagnosis of a pilocystic astrocytoma was possible. In the second of these cases (case 4), a 44-year-old male presented with a 3 year history of progressive right hand weakness and a 2 month his- 
tory of progressive dysphasia. A CT scan demonstrated a nonenhancing, low density mass in the left basal ganglia. A stereotactic biopsy was performed and the tissue obtained demonstrated necrosis and perivascular cuffing. A subsequent open biopsy was performed and identical tissue obtained. No specific diagnosis was made.

Among these seven patients, two developed postoperative complications. In the first (case 1), a patient with a mucormycosis abscess, a postoperative seizure occurred. A subsequent CT scan demonstrated only a small haematoma and a slight increase in the perilesional oedema. Although amphotericin B therapy was begun, the lesion progressively enlarged and the patient expired within 4 days. The second complication occurred in Case 4 and consisted of a mild transient postoperative increase in right hand weakness.

In five of the seven patients biopsied with this technique, general anaesthesia was employed and the procedures ranged in duration from 4-8 hours. The prolonged time for these procedures was based largely upon inexperience, and transportation from the operating room to the CT suite. In the 7th case, the procedure was performed under local anaesthesia utilizing the CT suite and an adjacent room for the entire procedure, which was performed in slightly over 2 hours. This was felt to represent the optimal way in which this technique could be done.

\section{GILDENBERG TECHNIQUE}

Eleven patients have been biopsied (table 2). In all patients, a satisfactory microscopic tissue diagnosis was obtained by the stereotactic biopsy. In one (case 10), a diagnosis of radiation necrosis made from the stereotactic biopsy was confirmed by an open biopsy. However, in this larger specimen, viable neoplasm was also found. In the remaining 10 patients, the diagnosis of a malignant tumour was made from the stereotactic biopsy. In one patient there was transient increase in facial asymmetry, which cleared within a week, (case 15), and in a 2 nd patient transient increase in right hemiparesis was seen (case 17). There were no significant intraoperative complications. All procedures were performed under local anaesthesia and required from 2-4 hours of operating room time and from 10-20 minutes of CT time.

\section{TARGET POINT SELECTION}

In seven of the last 11 lesions biopsied, a general pattern of a ring enhancing lesion with a low density center has been present. In all seven of those lesions, biopsy of the enhancing rim has resulted in a satisfactory tissue diagnosis. In three of the seven, additional biopsies were made in the low density center of the lesion. In only one of these three was viable tumour seen. All three, however, had evidence of necrosis which was useful in categorising the tumour as a glioblastoma multiforme in contradistinction to an anaplastic astrocytoma. ${ }^{34}$

\section{Discussion}

Both techniques used in this study were effective in obtaining diagnostic tissue. Nevertheless, certain advantages and disadvantages of each of the techniques were obvious. The use of a CT-guided stereotactic frame allowed performance of intracranial biopsies with an extremely high degree of accuracy. In the Modified Frame technique used in this study, an accuracy of $1 \mathrm{~mm}$ was established in phantom and cadaver experiments. However, the use of this frame generally requires one and a half to two hours of CT time and is only feasible where there is a dedicated CT scanner for this purpose. Since this does not exist in most institutions, a technique such as described by Gildenberg has a major practical advantage.

From our study, equivalent practical accuracy was achieved by both techniques. The saving of CT time and overall ease of using the Gildenberg technique are the major reasons for our present predominant use of this system. However, the high degree of accuracy achieved with the Modified Frame technique still makes this the procedure of choice for extremely small lesions or for lesions which are placed in sensitive positions.

With either technique, we feel that several target points should be chosen for each patient. This provides a greater chance of obtaining the correct diagnosis, especially with ring enhancing lesions. From the comparison of necropsy material obtained subsequent to CT scanning and our experience with the stereotactic biopsies, it can be seen that the radiographic and histologic findings are similar. ${ }^{34}$ These ring enhancing lesions, which most commonly represent malignant gliomas, have three general areas both histologically and radiographically: a low density centre on CT which represents necrotic tissue, an enhancing rim which has a histologically malignant pattern and a low density surrounding zone which has a mixture of anaplastic changes and grossly normal tissue with oedema. For the majority of our biopsies on such lesions, specimens taken in the enhancing rim have been the most helpful diagnostically although when this is coupled with evidence of necrosis from the low density centre of the lesion, the diagnosis of a glioblastoma can be made with greater confidence. Biopsies taken even a few millimeters outside of the enhancing rim have often failed to be diagnostic. Since these tumours fre- 
quently are spherical in shape and because of the partial volume averaging on CT scan, it can be easily seen why biopsies taken from target points on the outside edge of the enhancing rim may fail to be diagnostic. Evaluation of patients with ring enhancing lesions following chemotherapy, radiation therapy and surgery for malignant gliomas has demonstrated similar findings. ${ }^{16}$ In seven patients undergoing surgical resection of recurrent ring enhancing lesions, sections from the low density geometric centre of the lesion demonstrated cellular necrosis without evidence of viable tumour. Biopsies obtained at the enhancing rim or edge of the mass demonstrated a margin of tumour joining brain and gradually merging into normal appearing brain.

The coupling of CT and stereotactic surgery now enables deep-seated intracranial lesions to be accurately and safely biopsied. This alone represents a major advance; however, the potential ramifications of this technology, most notably the precise placement of interstitial irradiation and laser-coupled tumour resection, may prove to be more valuable in the future.

In summary, either the modified frame technique or the Gildenberg technique allows samples of intracranial tissue to be obtained safely and efficiently. The technique chosen should be a function of the available CT facilities and the degree of precision with which a lesion must be evaluated and biopsied.

We thank Drs W Jerry Oakes, Robert H Wilkins, Allan Friedman, S Clifford Schold, Peter Trillo, and Roger Bird for their support and encouragement in this project. We thank Mrs Rose Hagan for assistance in preparing this manuscript.

\section{References}

' Boethius J, Bergstrom M, Greitz T. Stereotaxic computerised tomography with a GE scanner.J Neurosurg 1980;52: 794-800.

${ }^{2}$ Brown RA. A computerised tomography-computer graphics approach to stereotaxic localisation. $J$
Neurosurg 1979;53:715-20.

${ }^{3}$ Burger PC, Dubois PJ, Schold SC, et al. Computerised tomographic and pathologic studies on the untreated, quiescent, and recurrent glioblastoma multiforme. $J$ Neurosurg 1983;58:159-69.

${ }^{4}$ Burger PC. Pathologic anatomy and CT correlations in the gioblastoma multiforme. J Appl Neurophysiol 1983 (in press)

5 Gleason CA, Wise BL, Feinstein B. Stereotactic localisation (with computerised tomographic scanning), biopsy, radiofrequency treatment of deep brain lesions. Neurosurgery 1978;2:217-22.

6 Jacques S, Sheldon CH, McCann GD. A computerised microstereotactic method to approach, 3-dimensionally reconstruct, remove and adjuvantly treat small CNS lesions. Appl Neurophysiol 1980;43: 176-82.

${ }^{7}$ Kelly PJ, Alker GJ Jr. A method for stereotactic laser microsurgery in the treatment of deep-seated CNS neoplasms. Appl Neurophysiol 1980;43:210-5.

${ }^{8}$ Lunsford LD, Rosenbaum AE, Perry J. Stereotactic surgery using the "therapeutic" CT scanner. Surg Neurol 1982;18:116-22.

${ }^{9}$ Maroon JC, Bank WO, Drayer BP, Rosenbaum AE. Intracranial biopsy assisted by computerised tomography. J Neurosurg 1977;46:740-4.

${ }^{10}$ Ostertag CB, Mennel HD, Kiesslıng M. Stereotactic biopsy of brain tumours. Surg Neurol 1980;14:27583.

"Dubois PJ, Nashold BS, Perry J, et al. CT-guided stereotaxis using a modified conventional stereotaxic frame. AJNR 1982;3:345-51.

12 Cail WS, Morris JL. Localisation of intracranial lesions from CT scans. Surg Neurol 1979;11:35-7.

${ }^{13}$ Gildenberg PL, Kaufman HH, Krishna Murthy KD. Calculation of stereotactic coordinates for the computed tomographic scan. Neurosurgery 1982;10:580-6.

${ }^{14}$ Bullard DE, Nashold BS, Osborne D, et al. Experience using two CT guided stereotactic biopsy methods. Appl Neurophys 1983;46:188-92.

is Schold SC, Cairncross JG, Bullard DE. Chemotherapy of primary brain tumours, in Wilkins $\mathrm{RH}$ and Rengachary SS, eds.; Neurosurgery, McGraw Hill, New York (in press).

${ }^{16}$ Selker RG, Mendelow H, Walker, et al. Pathological correlation of CT ring in recurrent previously treated gliomas. Surg Neurol 1982;17:251-4. 